\title{
Magnetization Process and Magnetic Microstructure of Nd-Fe-B HDDR Magnets
}

\author{
T. Maki and S. Hirosawa \\ Hitachi Metals, Ltd., 2-15-17 Egawa, Shimamoto-cho, Mishima-gun, Osaka 618-0013, Japan
}

\begin{abstract}
The magnetization process of an $\mathrm{Nd}-\mathrm{Fe}-\mathrm{B}$ hydrogenation-disproportionation-desorption-recombination (HDDR) magnet was studied by measuring its initial recoil curves. When compared with those of Nd-Fe-B sintered, HDDR and melt-spun magnets, the behavior of the initial recoil curves of the HDDR magnet was similar to that of the sintered magnet when the applied magnetic field was relatively small. The behavior of the initial recoil curves of the HDDR magnet became similar to that of the melt-spun magnet when the applied field became larger. The magnetic microstructure of the HDDR magnet was observed by means of a magnetic force microscope (MFM). When the HDDR magnet was thermally demagnetized, the distance of two domain walls was smaller than the average grain size of the HDDR magnet. On the other hand, the distance of two domain walls was larger than the average grain size of the HDDR magnet when the magnet was magnetically demagnetized. These results suggest that the HDDR magnet contains a multi-domain structure when the magnet is thermally demagnetized or when the applied field is relatively small. However, the HDDR magnet has only a single-domain structure after the application of sufficiently large fields.
\end{abstract}

Key words: $\mathrm{HDDR}$, magnetization process, $\mathrm{MFM}, \mathrm{Nd}_{2} \mathrm{Fe}_{14} \mathrm{~B}$, recoil curve

\section{Nd-Fe-B 系 HDDR 磁粉の磁化過程および磁区構造変化 \\ 槙 智仁・広沢 哲 \\ 日立金属株式会社，大阪府三島郡島本町江川 2-15-17（广618-0013）}

\section{1. はじめに}

$\mathrm{Nd}-\mathrm{Fe}-\mathrm{B}$ 系HDDR磁粉は $0.3 \mu \mathrm{m}$ 程度の微細な結晶粒を 有しており1),2)，磁粉状態で高保磁力が得られること，異方 性化が可能であることから異方性ボンド磁石用磁粉として 広く用いられている。 $\mathrm{Nd}-\mathrm{Fe}-\mathrm{B}$ 系材料の主相である $\mathrm{Nd}_{2} \mathrm{Fe}_{14} \mathrm{~B}$ 化合物は単磁区となる臨界粒径が $0.3 \mu \mathrm{m}$ 以下と 計算されており ${ }^{3), 4)}$, HDDR磁粉の結晶粒径が単磁区臨界粒 径付近であることからその磁区構造が多磁区であるか単磁 区であるかははっきりしていない. Ueharaら5), Thompson ら6) はNd-Fe-B系HDDR磁粉の磁区構造をローレンツ顕微 鏡によって観察し, 熱消磁状態においては結晶粒内に磁壁 が存在することを報告している。しかしながら，TEMによ る磁区観察においては薄膜試料作製中の表面欠陥の生成と それに伴う磁区構造変化の可能性が否定できない。 また磁 区観察により得られる情報は局所的であるため, HDDR磁 粉の磁区構造については全体の磁気的挙動を理解した上で 総合的に議論する必要がある.

筆者らは以前に， $\mathrm{Nd}-\mathrm{Fe}-\mathrm{B}$ 系磁石のリコイルカーブと単 磁区粒子を仮定した計算によるリコイルカーブの比較から, HDDR磁粉は着磁後の減磁過程において磁壁移動を含まな い単磁区的挙動であることを報告した7)。本報告では $\mathrm{Nd}-\mathrm{Fe}-\mathrm{B}$ 系焼結磁石, HDDR磁粉, 超急冷磁粉の初磁化過 程のリコイルカーブを測定し, 磁気的挙動の違いを比較し た。さらにバルク試料を用いた磁区観察によって初磁化お よび減磁過程における磁区構造を調べ，リコイルカーブ測 定から得られた結果と合わせてHDDR磁粉の磁化過程およ
び磁区構造変化を考察した.

\section{2. 実験方法}

試料は等方性試料として $\mathrm{Nd}-\mathrm{Fe}-\mathrm{B}$ 系等方性焼結磁石，等 方性 HDDR 磁粉および Nd-Fe-B 系単相超急冷磁粉の 3 種 類，異方性試料として $\mathrm{Nd}-\mathrm{Fe}-\mathrm{B}$ 系異方性 HDDR ボンド磁 石（日立金属(株製 High-B 材）を用意した。各試料の特徵 を Table. 1 に示す．等方性焼結磁石および異方性 HDDR ボンド磁石は $2.8 \mathrm{~mm}$ 角のものを用意した。等方性 HDDR 磁粉および単相超急冷磁粉は直径 $300 \mu \mathrm{m}$ 以下の球状粉末 および扁平状粉末をパラフィンで固めて VSM 用試料とし た。なお等方性試料については磁界配向を行わなかった。 初磁化過程のリコイルカーブ測定には超電導 VSM を用い て行った。 40 400 kA/m 刻みでリコイルカーブを測定し, 最大印加磁界は $4000 \mathrm{kA} / \mathrm{m}$ とした。 なお測定結果に対し反 磁界補正は行わなかった。

磁区観察用試料には配向方向を明確にするため，異方性

Table 1 Characteristics of samples.

\begin{tabular}{|c|c|c|c|c|}
\hline & $\begin{array}{c}\text { Sample } \\
\text { description }\end{array}$ & $\begin{array}{c}\text { Rare-earth } \\
\text { content } \\
(\text { at\% })\end{array}$ & $\begin{array}{c}\text { Grain } \\
\text { size } \\
(\mu \mathrm{m})\end{array}$ & $\begin{array}{c}\text { Coercivity } \\
(\mathrm{kA} / \mathrm{m})\end{array}$ \\
\hline \hline \multirow{3}{*}{ Isotropic } & Sintered & 14.0 & 5 & 1196 \\
\cline { 2 - 5 } & HDDR & 12.8 & 0.3 & 1255 \\
\cline { 2 - 5 } & Melt-spun & 13.2 & 0.05 & 1307 \\
\hline Anisotropic & HDDR & 12.2 & 0.3 & 915 \\
\hline
\end{tabular}



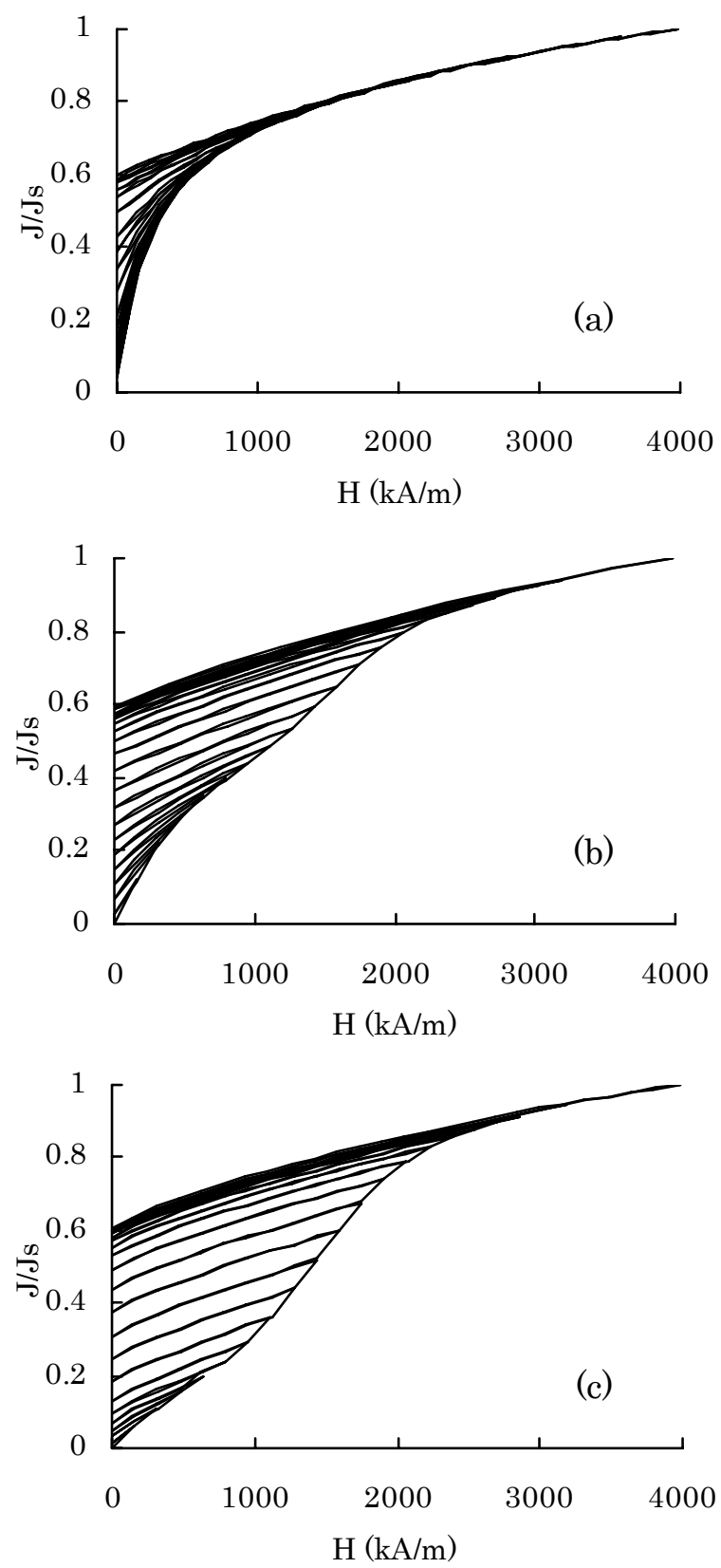

Fig. 1 Initial recoil curves of isotropic (a) sintered, (b) HDDR, and (c) melt-spun magnets.

HDDR ボンド磁石の配向方向に垂直な面をアルミナバフ 研磨したものを用いた. 観察には磁気力顕微鏡 (MFM) を 用いた。試料の着磁・減磁はパルス着磁機を用い, 同一試 料で熱消磁状態および磁界消磁状態（着磁磁界 $4000 \mathrm{kA} / \mathrm{m}$ 印加後に減磁磁界 $1000 \mathrm{kA} / \mathrm{m}$ 印加）の磁区観察を行った.

\section{3. 結果}

\section{1 初磁化過程のリコイルカーブ}

Fig. 1 に Nd-Fe-B 系等方性焼結磁石, 等方性 HDDR 磁 粉, 単相超急冷磁粉の初磁化リコイルカーブ測定結果を示

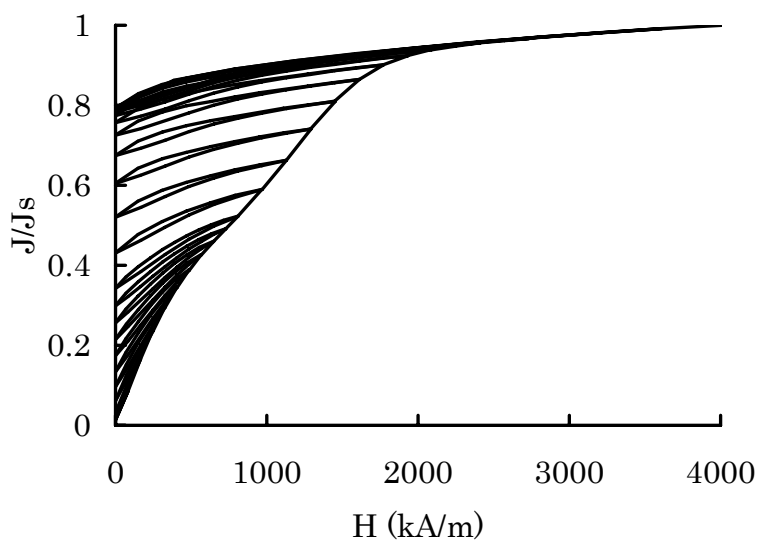

Fig. 2 Initial recoil curves of an anisotropic $\mathrm{Nd}-\mathrm{Fe}-\mathrm{B}$ HDDR bonded magnet.

す. Fig. 1(a)の等方性焼結磁石は比較的小さい印加磁界で 急激に磁化され，リコイルカーブは急峻な傾きを有する曲 線となった. またFig. 1(c)に示した単相超急冷磁粉のリコ イルカーブは第一象限において印加磁界の大小によらず直 線的で互いに平行であった。これらの挙動は減磁過程にお けるリコイルカーブの挙動と同様であり7), 焼結磁石が磁壁 移動を含む多磁区構造の磁化過程, 単相超急冷磁粉が磁壁 移動を含まない単磁区構造の磁化過程であることを示して いる. 一方Fig. 1(b)の等方性HDDR磁粉においては, 低印 加磁界 $(\mathrm{H}=0 \sim 800 \mathrm{kA} / \mathrm{m})$ ではリコイルカーブは比較的急 峻な傾きを示したが，それ以降では互いに平行な直線に変 化していた。この挙動は低印加磁界側においては焼結磁石 に近く, 高印加磁界側においては単相超急冷磁粉と同様で あるといえる、このことから，等方性HDDR磁粉は熱消磁 状態から低磁界を印加した時点までは多磁区構造が含まれ た磁区構造であり，より高磁界を印加した後には単磁区構 造のみとなっている可能性がある.

次にリコイルカーブの挙動におよぼす配向度の影響を調 ベるため, 異方性 HDDR ボンド磁石の初磁化リコイルカー ブを測定した結果を Fig. 2 に示す.なお試料は特殊な方法 で配向させており, 測定前は熱消磁状態と同じ状態を保っ ている. 異方性 HDDR ボンド磁石においても等方性 HDDR 磁粉と同様な挙動を示しており，上述した磁区構造は配向 度に関わらず存在すると考えられる。

\section{2 M F Mによる磁区観察}

異方性 HDDR ボンド磁石の配向方向に垂直な面の MFM 観察結果を Fig. 3 に示す．なお紙面前方に向かう磁束は明 るく, 紙面後方に向かう磁束は暗く表示されている. Fig. 3(a)に熱消磁状態の MFM 像を示す. MFM 像における明暗 の境界が磁壁の位置であるとすると，隣り合う磁壁の間隔 は $1 \mu \mathrm{m}$ 以下のものがほとんどであった. Fig. 3(b)に示し た熱消磁状態の MFM 像を一部拡大した図を見ると, 矢印 で示した部分に代表されるように隣り合う磁壁の間隔が 

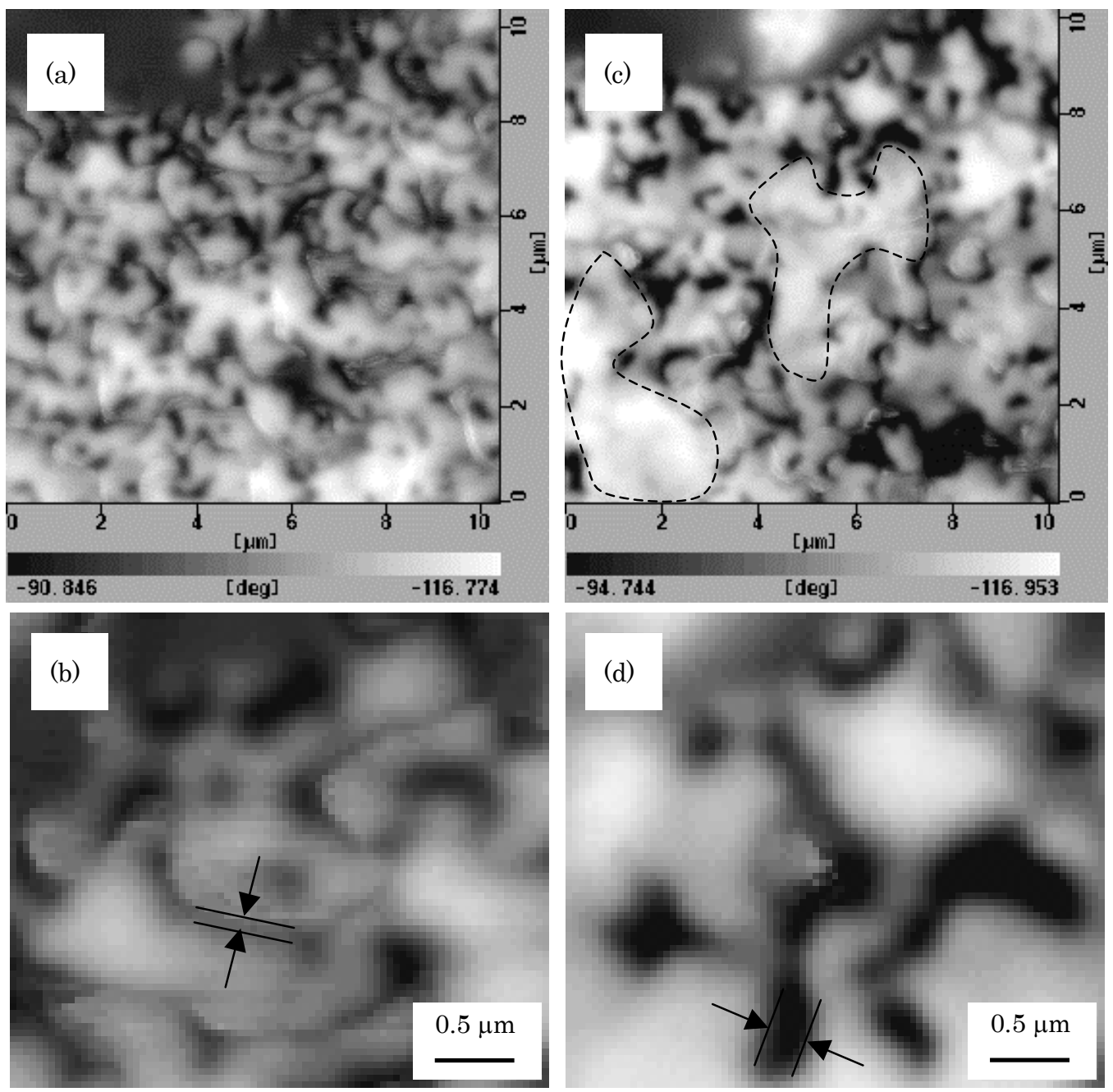

Fig. 3 MFM images of the thermally demagnetized state (a), (b) and magnetically demagnetized state (c), (d) of an $\mathrm{Nd}-\mathrm{Fe}-\mathrm{B}$ HDDR bonded magnet.

0.1〜0.3 $\mu \mathrm{m}$ で連続的に存在する様子が観察された.この 間隔は HDDR 磁粉の平均結晶粒径 $0.3 \mu \mathrm{m}$ よりも狭く, 結 晶粒界に沿って磁壁が存在するとは考えにくい. 従って磁 壁は結晶粒界・粒内に関わらす存在しており，熱消磁状態 の HDDR 磁粉には多磁区構造が存在していることを示し ていると考えられる.

続いて着磁磁界 $4000 \mathrm{kA} / \mathrm{m}$ を印加した後, 減磁方向に磁 界 $1000 \mathrm{kA} / \mathrm{m}$ を印加して磁界消磁状態とした試料の MFM 像を Fig. 3(c)に示す。熱消磁状態の MFM 像と比較すると 磁壁間隔は拡がっており，Fig. 3(d)の拡大図において矢印 で示すように磁壁間隔は $0.3 \mu \mathrm{m}$ 以上であった.これは磁壁 が結晶粒内から取り除かれた可能性を示しており，着磁後 の減磁過程においては多磁区構造がほとんど存在していな いと考えられる．以上のことは，初磁化リコイルカーブお よび減磁リコイルカーブから推察した内容と一致している. さらに, Fig. 3(c)に示した磁界消磁状態の MFM 像から は図中破線部分のように連続する磁壁に囲まれた一つの磁 区の大きさが $3 \sim 4 \mu \mathrm{m}$ のものが観察された。これは数 $\mu \mathrm{m}$
範囲で結晶粒の磁化が同方向を向いていることを表してい る.減磁過程において HDDR 磁粉の各結晶粒は単磁区構造 となっているが，磁化反転の際には個々の結晶粒が独立に 反転するのではなく，ある程度まとまった範囲の結晶粒で 形成された磁区の境界が移動する形で磁化反転している可 能性がある，その場合，保磁力を決めているのは磁区境界 において磁壁の移動を妨げている組織や構造であると予想 される。

\section{4. まとめ}

$\mathrm{Nd}-\mathrm{Fe}-\mathrm{B}$ 系等方性焼結磁石，等方性 HDDR 磁粉，単相 超急冷磁粉の初磁化リコイルカーブを測定した結果，等方 性 HDDR 磁粉は低磁界において焼結磁石に近く, 高磁界に おいて単相超急冷磁粉と同様な挙動を示した。この挙動は 異方性 HDDR ボンド磁石においても確認された.

異方性 HDDR ボンド磁石の MFM 観察を行った結果, 熱消磁状態では隣り合う磁壁の間隔が平均結晶粒径よりも 
狭いものが観察されたが，磁界消磁状態における磁壁の間 隔は平均結晶粒径以上であった。

以上の結果から, $\mathrm{Nd}-\mathrm{Fe}-\mathrm{B}$ 系 HDDR 磁粉は熱消磁状態 から低磁界を印加した時点までは多磁区構造が含まれた磁 区構造であるが，より高磁界を印加した後には単磁区構造 のみとなっていると考えられる.

また, 磁界消磁状態の MFM 像からは連続する磁壁に囲 まれた一つの磁区の大きさが $3 \sim 4 \mu \mathrm{m}$ ののが観察された. このことは, HDDR 磁粉は減磁過程において結晶粒の集団 で形成された磁区の境界が移動する形で磁化反転している 可能性があることを示している.今後はこのような集団の 挙動が組織や構造を変化させたときに受ける影響を明らか にすることで，減磁過程および保磁力に対する理解がより 深まると思われる。

謝辞 磁区観察にご協力いただいた静岡理工科大学 小林 久理眞教授，早川一生氏に感謝致します.

\section{References}

1) T. Takeshita and R. Nakayama: Proceedings of 10th International Workshop on Rare-Earth Magnets and Their Applications at Kyoto, Vol. 1, 551 (1989).

2) T. Takeshita and R. Nakayama: Proceedings of 12 th International Workshop on Rare-Earth Magnets and Their Applications at Canberra, 670 (1992).

3) M. Sagawa, S. Fujimura, H. Yamamoto, Y. Matsuura, S. Hirosawa and K. Hiraga: Proceedings of 4th International Symposium on Magnetic Anisotropy and Coercivity in Rare Earth-Transition Metal Alloys at Dayton, 587 (1985).

4) J. D. Livingston: J. Appl. Phys., 57, 4137 (1985).

5) M. Uehara, T. Tomida, H. Tomizawa, S. Hirosawa and Y. Maehara: J. Magn. Magn. Mater., 159, L304 (1996).

6) P. Thompson, O. Gutfleisch, J. N. Chapman and I. R. Harris: J. Phys. D, 30, 1854 (1997).

7) 槙, 広沢: J. Magn. Soc. Jpn., 31, 189 (2007).

2007 年 10 月 4 日受理, 2008 年 2 月 14 日採録 